\title{
A PESQUISA-AÇÃO E A EDUCAÇÃO EM SAÚDE AMBIENTAL NOS SERVIÇOS DE SAÚDE DO SUS
}

\author{
THE ACTION-RESEARCH AND EDUCATION IN HEALTH \\ ENVIRONMENTAL HEALTH SERVICES IN THE SUS \\ Maria de Lima Alves ${ }^{1}$; Maria de Fátima Freired Melo Ximenes ${ }^{2}$; Magnolia Fernandes \\ Florêncio de Araújo ${ }^{3}$ \\ ${ }^{1}$ Mestra pelo Programa Regional de Pós-Graduação em Desenvolvimento e Meio Ambiente - \\ PRODEMA/UFRN; e-mail: malimabio@bol.com.br \\ ${ }^{2}$ Professora do Departamento de Microbiologia e Parasitologia - UFRN. Doutora pelo Instituto Nacional \\ de Pesquisa da Amazônia - INPA. e-mail: ximenes@cb.ufrn.br \\ ${ }^{3}$ Professora do Departamento de Microbiologia e Parasitologia - UFRN. Doutorado em Ecologia e \\ Recursos Naturais. e-mail: mag@cb.ufrn.br
}

\begin{abstract}
RESUMO
Atividades educacionais que transcendem os limites da sala de aula podem ser contempladas em diferentes ambientes através de práticas e condições educativas direcionadas para suas necessidades. Ações educativas no campo da saúde ambiental nos estabelecimentos de saúde são necessárias diante da crescente demanda das questões ambientais nestes serviços. O objetivo consistiu em difundir os princípios da educação em saúde ambiental para os profissionais dos estabelecimentos de saúde do SUS em Mossoró-RN através da metodologia da pesquisa-ação. Diferentes fases metodológicas foram percorridas contribuindo para o envolvimento entre os sujeitos da pesquisa, a pesquisadora e a temática favorecendo reflexões acerca das responsabilidades individuais e coletivas das questões ambientais em saúde e da necessidade de mudanças de atitudes que promovam a saúde dos indivíduos e a qualidade do ambiente nos serviços de saúde do SUS.
\end{abstract}

Palavras-Chave: Pesquisa-ação; Educação ambiental; Saúde Ambiental; SUS.

\begin{abstract}
Educational activities that transcend the limits of classroom can be contemplates in different environments through of practices and educational conditions directed for your needs. Educational actions in the field of environmental health in the establishments of health are necessary face of the growing demand environmental issues in these services. The aim consisted in spreading the principles of education in environmental health for the professionals of the establishments of SUS health in Mossoro-RN through the methodology of the action research. Different methodological phases were covered contributing to the engagement between the research subjects, the researcher and the thematic, favoring reflections about of the responsibilities individual and collective of the issues of the environmental health and the need for changes in attitudes that promote the health of the individuals and the quality of the environment in health services of the SUS.
\end{abstract}

Keywords:Action-Research, Environmental Education, Environmental Health, SUS. 


\section{INTRODUÇÃO}

Atividades educacionais que transcendem os limites da sala de aula podem ser contempladas em diferentes ambientes através de práticas e condições educativas direcionadas para suas necessidades. A troca de saberes e experiências no processo ensino-aprendizagem apresentam-se como algo inseparável a este processo não se limitando ao processo educativo formal. Esta perspectiva vem norteando ações educativas diferenciadas em ambientes e territórios distintos. Como destaca a UNESCO,

É comum focalizar o sistema educacional formal como lugar de aprendizagem. Entretanto, aprende-se tanto dentro quanto fora do sistema escolar, nas interações da vida cotidiana, na família, no trabalho, frente ao computador ou televisão, observando, copiando, experimentando, refletindo, articulando, ouvindo e aprendendo com os erros (UNESCO, 2005, pag.58).

Assim, o educador pode transitar entre o formal e o não formal, quando da organização de um ambiente de aprendizagem, dependendo de como irá desenvolver a prática educativa. No ambiente formal, o educador fornece as condições necessárias ao processo educativo assumindo responsabilidades no planejamento, preparação do ambiente e avaliação. Já a aprendizagem num ambiente não formal, o educador atua como mediador das heterogeneidades educativas que envolvem diferentes situações, espaços e sujeitos. Onde o sujeito, descaracterizado do papel de aluno, aprende por meio da observação, discussão, interação com pessoas e o ambiente, não se preocupando em ser avaliado por aquilo que viu, ouviu e participou. O lugar de aprendizagem necessita ser apreendido quanto às diferentes características do lugar (MOREIRA, 2007).

\footnotetext{
"[...] o caráter socialmente construído de um ambiente de aprendizagem expressa a característica local das experiências vividas, dependentes dos papéis a que se atribuem nesse lugar, de suas expectativas e desejos, de como percebem uns aos outros, os materiais e sua organização e os resultados de suas ações... se valem dos recursos materiais e simbólicos disponibilizados pelo ambiente para concretizar suas interações". (MOREIRA, 2007, p.56)
}

Assim, o processo educativo e seus desdobramentos em ambientes educativos não formais, como o ambiente de trabalho, requerem aportes teórico-metodológicos capazes de suportar suas diferentes demandas cotidianas. No ambiente hospitalar a qualidade do ambiente vivenciado cotidianamente por seus profissionais interfere diretamente na qualidade das atividades desenvolvidas, sendo que seu inverso também é verdadeiro, necessitando de incrementos educacionais voltados para realidades ocupacionais específicas. De acordo com Alves (2008) o espaço de trabalho da maioria 
dos profissionais de serviços de saúde é o mesmo de acolhimento e assistência dos doentes e seus acompanhantes podendo interferir e comprometer as atividades laborais e a saúde daqueles que vivenciam o mesmo ambiente.

É indiscutível a afirmação de que as condições ambientais dentro dos estabelecimentos de saúde interferem na saúde dos indivíduos. Mas, abrangência da temática ambiental no setor saúde, interfere na resolutividade de suas questões, envolve diferentes setores, serviços e profissionais, colocando em pauta diferentes desafios. A qualidade e a promoção de ambientes saudáveis nos serviços de saúde, preconizada pelo SUS, ainda é uma questão pouco discutida e assimilada pela maioria de seus profissionais e gestores apresentando-se ainda como uma de suas novas demandas.

As condições ambientais desfavoráveis da maioria destes serviços são geradoras potenciais de impactos negativos ao meio ambiente com sérias implicações na saúde dos indivíduos representando riscos (químicos, físicos e biológicos) incalculáveis para a saúde coletiva, cujas fontes de poluição são distintas: alta produção de resíduos de serviços de saúde e deficiência no seu gerenciamento, emissão de gases perigosos, inadequado tratamento da água para consumo humano, destinação final imprópria para efluentes e resíduos, controle de pragas, dentre outros (BRASIL, 2006). Assim, as demandas e fatores ambientais que interferem na saúde dos indivíduos compõem o escopo de temáticas do campo da saúde ambiental.

Para o delineamento do processo investigativo deste estudo foi necessário incorporar os conceitos próprios do campo da saúde e do meio ambiente que comungam com os da saúde ambiental. Entretanto, do ponto de vista educacional foi necessário transpor as barreiras da hierarquia profissional e de suas práticas cotidianas a fim de se identificar quais atividades e processos educativos poderiam ser incorporados ao cotidiano destes profissionais no tocante às questões ambientais nos serviços de saúde.

Mas, como incorporar saberes ambientais aos processos de trabalho em saúde? Há possibilidade de melhoria da realidade ambiental nestes serviços? Os profissionais estão dispostos a contribuir com práticas adequadas à promoção de ambientes de trabalho saudáveis? Esses questionamentos foram imprescindíveis ao delineamento, desenvolvimento e incremento de ações educativas em saúde ambiental que pudessem contribuir para a minimização dos riscos inerentes aos estabelecimentos de saúde.

A partir da detecção das dificuldades cotidianas condizentes aos vários aspectos identificados em cada serviço, foi possível projetar as ações educativas. Considerou-se que essas ações poderiam, ao longo do processo, contribuir de forma significativa para ISSN 1983-7011 
atender as necessidades do conjunto de seus profissionais e gestores e a comunidade. Os aspectos práticos de concepção e organização desta proposta apresentaram fases que não foram rigorosamente seqüenciais, sendo seu planejamento feito de forma flexível e passível de adequação às necessidades do pesquisador e dos participantes.

Para tanto, adotou-se a metodologia da pesquisa-ação observando suas diferentes fases: inserção do pesquisador, diagnóstico situacional, campo de observação, amostragem e representatividade qualitativa, estratégia e plano de ação, aprendizagem e avaliação. Para Thiollent (2009) embora a pesquisa-ação privilegie o lado empírico sua abordagem deverá partir do referencial teórico, sem o qual não faria sentido.

A utilização deste método possibilitou o alcance dos objetivos propostos e o desenvolvimento de atividades educativas acerca das condições ambientais internas dos serviços de saúde para os profissionais de saúde em seus ambientes de trabalho. Apesar da existência de estudos cujas metodologias relatam experiências da pesquisa-ação no setor saúde no Brasil não se verificou ainda estudos referentes ao desenvolvimento e incremento de ações educativas em saúde ambiental para os profissionais de saúde sistematizadas a partir da realidade ambiental de cada serviço.

Assim, optou-se por desenvolver ações educativas voltadas para a promoção da saúde dos indivíduos e de ambientes saudáveis nos estabelecimentos de saúde. O objetivo deste artigo é descrever a trajetória metodológica da pesquisa-ação desenvolvida como processo investigativo em saúde ambiental nos serviços de saúde do Sistema Único de Saúde (SUS) em Mossoró-RN. Na tentativa de traçar uma trajetória para a fundamentação teórica do artigo inicialmente discorre-se sobre a pesquisa-ação e, posteriormente, sobre a saúde ambiental. A metodologia possibilitou o desenvolvimento de ações educativas em saúde ambiental para os profissionais de saúde a partir do conhecimento e da reflexão das condições ambientais de trabalho destes serviços.

\section{A metodologia da pesquisa-ação}

A pesquisa-ação é uma metodologia de pesquisa participante que vem contribuindo com o campo do saber científico procurando unir a pesquisa à ação prática trilhando um caminho oposto ao da pesquisa tradicional considerada como "independente" e "objetiva" (KETELE \& ROEGIERS, 1993). Este tipo de pesquisa contribui para a compreensão e a construção do conhecimento como parte da prática. No ambiente profissional constitui como um meio de desenvolvimento profissional de 
"dentro para fora" em que aborda as preocupações e interesses das pessoas envolvidas na prática (NUNAN, 1993).

De acordo com Engel (2000) a metodologia da pesquisa-ação surgiu da necessidade de superar a lacuna entre teoria e prática. Caracteriza-se por sua intervenção prática inovadora no decorrer do próprio processo de pesquisa e não apenas como uma recomendação na etapa final do projeto.

A pesquisa-ação vem sendo discutida em diferentes campos do conhecimento na literatura estrangeira. Um de seus pioneiros foi o psicólogo alemão Kurt Lewin com trabalhos na área da sociologia na década de 1960. Atualmente, vem sendo utilizada na área do ensino, meio ambiente e saúde bem como na psicologia e nas ciências sociais. De acordo com Engel (2000) além da área educacional, a pesquisa-ação pode ser aplicada em qualquer ambiente de interação social que se caracterize por um problema, no qual estão envolvidos pessoas, tarefas e procedimentos.

A pesquisa-ação no Brasil apresenta-se em dois momentos. O primeiro momento se aproxima do método utilizado pelos norte-americanos Lewin \& Corey através de análises dos conhecimentos provenientes das intervenções sociais em relação a determinado problema. Os sujeitos eram incentivados à participação nos ambientes onde desenvolviam suas atividades laborais não se limitando a incorporação de saberes técnicos adquiridos fora daquele ambiente. A metodologia utilizada por estes autores em suas pesquisas na área da educação foi considerada um avanço no campo do saber científico no Brasil passando a ser utilizada em diferentes áreas (MOREIRA, 2007).

O segundo momento surge a partir do método de Paulo Freire nas décadas de 1960 e 1970. Suas experiências educacionais se efetivaram nos setores populares da sociedade a partir das trocas de experiências vivenciadas pelos participantes através da reflexão quebrando certos valores e práticas de pesquisas e contribuindo para constantes modificações e redefinições destes aspectos na esfera acadêmica (FREIRE, 1993). De acordo com Molina (2007) o avanço da pesquisa-ação no Brasil ganha força com aproximação do ano 2000 e se apoia em uma diversidade de autores e correntes teóricas. Sua propagação ocorre a partir da década de 1980 através de pesquisas participantes, estudos de casos e etnográficos, historias de vida, dentre outros (Gatti, 2002). Neste período o pesquisador Michel Thiollent se destaca pela diversidade de propostas para a pesquisa-ação nos mais variados campos do saber.

Para Thiollent (2009) a pesquisa-ação é uma metodologia de pesquisa empírica, concebida e realizada em estreita associação com uma ação ou resolução de um ISSN 1983-7011 
problema coletivo, com a qual se estabelece o envolvimento cooperativo entre pesquisadores e participantes da situação problema. O desenvolvimento do estudo pelo método da pesquisa-ação proporciona ao pesquisador um papel ativo para intervir nos problemas, na organização e acompanhamento das ações.

A metodologia da pesquisa-ação contagiou pesquisadores em diferentes campos da pesquisa cientifica por sua flexibilidade metodológica e oportunidade de intervenção nas situações problemas identificada no locus da pesquisa. Franco (2005, p.497) considera a imprevisibilidade como um componente fundamental à prática da pesquisaação: "A metodologia da pesquisa-ação implica em considerar a complexidade, a imprevisibilidade, a oportunidade, gerados por alguns acontecimentos inesperados, a fecundidade potencial de alguns momentos que emergem da práxis".

A pesquisa-ação apresenta características peculiares enquanto modalidade investigativa através do incremento de procedimentos metodológicos mais flexíveis necessitando ajustar-se continuamente aos acontecimentos. Significa uma intervenção educativa que enfatiza o retorno dos resultados aos pesquisados, no decorrer da pesquisa contribuindo para o aumento no nível de conhecimento e de sensibilização dos participantes em relação aos problemas coletivos vivenciados (THIOLLENT, 2009).

Esta metodologia é sempre deliberativa porque, quando se intervém na prática rotineira, está se aventurando no desconhecido, de modo que é preciso fazer julgamentos competentes a respeito daquilo que mais provavelmente poderá contemplar a situação de forma mais eficaz (TRIPP, 2005, p.449). Deste modo, a pesquisa não se limita a ação. Pressupõe um incremento no nível de conhecimento e de intervenção dos sujeitos e do próprio pesquisador. Não se faz por meio de etapas rigorosas de um método, mas se organiza pelas situações relevantes que emergem do processo (THIOLLENT, 2009). Para Benevides \& Passos (2005) a utilização deste método de pesquisa na área da saúde, poderá trazer inúmeros benefícios, já que a educação para a saúde tem, intrinsecamente, realidades e paradigmas que urgem ser transformadas, tanto na área da saúde quanto na educação.

\section{Saúde ambiental}

A necessidade de introduzir a temática ambiental nos serviços de saúde permitiu a escolha de instrumentos metodológicos que incorporassem atividades e conhecimentos interdisciplinares condizentes com a realidade ambiental vivenciada pelos profissionais de saúde nos locais onde desenvolvem suas atividades laborais. 
Assim, por entender que a educação em saúde ambiental incorpora também o processo educativo não formal ela poderia ser utilizada como um meio para o desenvolvimento de atividades educativas voltadas para as questões ambientais no setor saúde. Para Tripp (2005) a questão é que a pesquisa-ação requer ação tanto nas áreas da prática quanto da pesquisa, de modo que, em maior ou menor medida, terá características tanto da prática rotineira quanto da pesquisa científica.

Até pouco tempo atrás, no setor Saúde, a dimensão de ambiente era compreendida pelos profissionais como externa a eles. Muitas vezes o ambiente era compreendido de forma romântica, através de ambientes perfeitos e intocáveis, traduzida pelas expressões "ambiente físico", "ecossistema" ou "espaço geográfico". Mais recentemente, a partir de um marco legal e normativo construído ao longo do tempo a partir de 2005 o tema foi ganhando relevância no Sistema Único de Saúde (SUS), principalmente a partir da incorporação da Vigilância Ambiental ao Sistema Nacional de Vigilância Epidemiológica e Ambiental em Saúde (SNVA). A partir de então, no âmbito do SUS, amplia-se a compreensão de que há um ambiente maior e relacional, em que as ações de promoção da saúde devem ser implementadas levando-se em consideração o ambiente onde as pessoas residem e trabalham (FUNASA, 2000).

A saúde ambiental tem por finalidade consolidar ações e estudos que contribuam para proteger e promover a saúde humana dos determinantes socioambientais, inclusive na prevenção dos agravos decorrentes da exposição humana a ambientes adversos. Esta proposta vem sendo construída através de programas e políticas específicas por meio de ações integradas entre a sociedade, o setor saúde, educação e do meio ambiente nas três esferas governamentais: União, Estados e Municípios (BRASIL, 2006).

O conceito de saúde ambiental vem sendo trabalhado de forma ampliada a partir da reforma sanitária entendido como um processo de transformação num contexto democrático de práticas saudáveis no que diz respeito à saúde humana e ambiental (8080/90). Vem contribuindo de forma significativa para a compreensão do processo saúde doença nos indivíduos, concretizado através do direito universal a saúde e de um ambiente ecologicamente equilibrado em consonância com os princípios e diretrizes do SUS (BRASIL, 2006).

A diversidade de problemas que envolvem a temática ambiental tornou relevante a adoção da pesquisa-ação como abordagem metodológica. Schall \& Stuchiner (1999) consideram que a pesquisa-ação aproxima-se intimamente dos novos paradigmas da Educação para a Saúde, pois “(...) deve-se levar em consideração as representações dos ISSN 1983-7011 
sujeitos podendo ser entendidas como noções e modos de pensamento e construídos ao lado das trajetórias de vida desses sujeitos (...)". Entretanto, do ponto de vista metodológico, estas abordagens estão em processo de construção, García (1999, p.41):

\begin{abstract}
“Os estudos sobre a problemática ambiental evidenciaram, de maneira reiterada, a insuficiência das metodologias tradicionais (ou, mais exatamente, do que tradicionalmente se entende por metodologia) para realizá-los. Dali a elaborar propostas concretas que constituam verdadeiras alternativas para realizar estes estudos, e que reúnam, além disso, a indispensável condição de serem operativas, quer dizer, de traduzir-se em procedimentos mais ou menos precisos que orientem as investigações, há um longo caminho cheio de dificuldades. Como ocorre em todos os campos, é mais fácil colocar-se de acordo sobre o que devemos abandonar e superar em velhas práticas de investigação, do que concordar em uma proposta superadora."
\end{abstract}

Assim, pesquisas que envolvem a saúde ambiental como área temática de estudo e de práticas no setor saúde e meio ambiente vem se consolidando no Brasil. Augusto (2002) alerta que é necessário o pensamento complexo, “... que admite escapar da visão mecânica, determinista, de causalidade linear”. Conforme Samaja (2000), os problemas de desenvolvimento dos indivíduos são inseparáveis do ambiente de desenvolvimento social das populações envolvidas e inseparáveis dos problemas da reprodução e do desenvolvimento das sociedades.

O campo da saúde ambiental no Brasil vem abrindo novos horizontes para além do debate sobre o saneamento básico e as doenças infectocontagiosas, enfocando problemas como agrotóxicos, metais pesados, destinação de resíduos, contaminação das águas para consumo humano, ambiente urbano, entre outros sugerindo caminhos para uma política de saúde ambiental que venha responder à complexa estrutura de nossa sociedade. A saúde ambiental apresenta-se como um novo protagonista no setor saúde a partir da incorporação de pesquisadores e profissionais do campo da saúde coletiva e de meio ambiente considerando um quadro normativo legal (BRASIL, 2006). Para Lieber (1998) o reconhecimento das multicausas e a importância dos contextos socioambientais e culturais no cotidiano dos indivíduos são fundamentais para transformar as nocividades geradas pela ação do homem no ambiente e melhorar a qualidade de vida.

Em alguns aspectos, a gestão de riscos que compreende a geração, controle, tratamento e destino final de contaminantes, já está previsto na Política Nacional do Meio Ambiente (Lei 6.938/81) e em Estudos de Impactos Ambientais (RDC CONAMA 1/86) executado pelo IBAMA e pelos órgãos estaduais e municipais de meio ambiente. Já a agenda 21 brasileira destaca aspectos referentes aos fatores ambientais que 
interferem na saúde humana onde a ecologia não está centrada apenas nos aspectos bioecológicos, mas também nos socioculturais, reconhecendo-a como uma ciência de inter-relações (BRASIL, 2000).

A ecologia, assim como a saúde, atravessa diversos campos disciplinares. Seu entendimento é fundamental para fortalecer o conceito mais amplo de saúde onde existe alguma forma de consenso para a promoção da saúde dos indivíduos e da sustentabilidade dada à importância da participação local dos indivíduos e da revisão da forma como vivem e trabalham (AUGUSTO et al., 2001).

Portanto, se faz necessário conhecer os diferentes conceitos acerca da temática da sustentabilidade, que por sua vez, é um conceito novo e que serve para traduzir um tipo de desenvolvimento sob um real Estado de Direito, sem iniqüidades, baseado na concepção de mundo como um conjunto de "sistemas inter-relacionados (complexos), do qual fazemos parte como seres culturais por natureza e naturais por cultura" (GARCÍA, 1999). No entanto, o discurso do Desenvolvimento Sustentável não é homogêneo e se diferencia em função dos interesses ambientais de diversos setores sociais, políticos e econômicos envolvidos no processo de desenvolvimento e implica em modificações econômicas e sociais profundas (LIEBER, 1998).

\section{METODOLOGIA}

A análise empreendida neste artigo dedicou-se a mostrar a trajetória da pesquisaação como metodologia de investigação científica em estabelecimentos de saúde do Sistema Único de Saúde (SUS) do município de Mossoró-RN. Para tanto, foi imprescindível a seleção e o diagnóstico prévio dos estabelecimentos de saúde para a sistematização e desenvolvimento de atividades educativas com a temática da saúde ambiental. As ações educativas se realizaram no período de março a outubro de 2007. A metodologia permitiu percorrer as diferentes fases da pesquisa-ação: diagnóstico situacional, campo de observação, amostragem e representatividade qualitativa, coleta de dados, estratégia e plano de ação e avaliação as quais serão descritas seguindo uma ordem cronológica de acordo com sua realização.

Para tanto, tomou-se como referência legislações e políticas da área da saúde e do meio ambiente, como: RDC 358/2005 do Conselho Nacional de Meio Ambiente, sobre os resíduos de serviços de saúde; RDC 304/2004 da Agência Nacional de Vigilância Sanitária, que trata do gerenciamento de resíduos de serviços de saúde; NR 32/2005 do Ministério do Trabalho e Emprego, sobre a segurança e saúde no trabalho 
em serviços de saúde; Lei 8080/90 que disciplina a descentralização políticoadministrativa do SUS; Lei 8142/90 que regulamenta a participação da comunidade e as transferências intergovernamentais de recursos financeiros no âmbito do SUS.

\section{RESULTADOS E DISCUSSÕES}

A metodologia da pesquisa-ação apresenta aspectos práticos de concepção e organização do trabalho apresentando fases que não são rigorosamente seqüenciais, sendo seu planejamento flexível e passível de adequação às necessidades do pesquisador e dos participantes (THIOLLENT, 2009). Assim, serão descritas a seguir as ações desenvolvidas nos estabelecimentos de saúde durante a pesquisa.

\section{$1^{\text {a }}$ Fase - Inserção do (a) Pesquisador (a)}

Diante do desafio de pesquisar a problemática ambiental nos estabelecimentos de saúde na cidade de Mossoró-RN, surgiu um questionamento na fase inicial da pesquisa: Como coletar dados referentes ao meu objeto de estudo, sem deter pouca ou nenhuma informação a respeito do manejo de resíduos e das questões ambientais destes estabelecimentos? Então, considerou-se que o reconhecimento dos sujeitos e das instituições antecederia a fase de diagnóstico, para posteriormente possibilitar a sistematização das atividades educacionais e de pesquisa.

Anterior à fase de diagnóstico efetivou-se o reconhecimento dos estabelecimentos onde seria realizada a pesquisa. Dessa forma, os sujeitos da pesquisa, profissionais de saúde e gestores, foram contatados na tentativa de conhecer a realidade dos estabelecimentos de saúde no que concerne aos recursos estruturais e humanos, a fim de apreender aspectos que contribuiriam para o planejamento e sistematização das atividades a serem desenvolvidas com a temática ambiental. Para tanto, foi importante identificar as diferenças contratuais, socioculturais e econômicas entre as categorias profissionais destas instituições de saúde.

Nessa perspectiva, utilizou-se a pesquisa-ação como uma ferramenta metodológica relevante que contribuiu para a investigação, a intervenção e a análise dessa realidade. Na medida em que se observava nesta proposição a flexibilidade metodológica como um de seus componentes essenciais e, portanto, pertinente com a complexidade que a pesquisadora se deparou ao adentrar no campo de pesquisa. A opção por essa abordagem metodológica faz uma ruptura com os modelos reducionista e positivista que submete o (a) pesquisador (a) a uma pseudoneutralidade em relação à 
situação problema encontrada. A inserção do (a) pesquisador (a) no campo de estudo, consente intervir e contribuir com o desenvolvimento de atividades de pesquisa voltadas para cada realidade, assegurando o rigor científico que toda pesquisa requer. Conforme Franco (2005, p. 490),

\begin{abstract}
"Desde sua origem a pesquisa-ação assume uma postura diferenciada diante do conhecimento, uma vez que busca, ao mesmo tempo, conhecer e intervir na realidade que pesquisa. Essa imbricação entre pesquisa e ação faz com que o pesquisador, inevitavelmente, faça parte do universo pesquisado, o que, de alguma forma, anula a possibilidade de uma postura de neutralidade e de controle das circunstancias de pesquisa".
\end{abstract}

Desta forma, antes de iniciar qualquer procedimento de coleta de dados foram realizadas visitas nos estabelecimentos de saúde onde a pesquisa se desenvolveria corroborando com a proposta metodológica da pesquisa-ação.

\title{
$2^{\mathrm{a}}$ Fase - Diagnóstico Situacional
}

$\mathrm{Na}$ fase inicial da pesquisa, foi feito um diagnóstico em doze estabelecimentos de saúde do município de Mossoró em diferentes níveis de complexidade permitindo identificar diferentes problemas ambientais. O diagnóstico situacional foi indispensável para identificar os problemas ambientais nestes serviços. O problema mais recorrente em todos os estabelecimentos de saúde foi o manejo de resíduos considerando sua periculosidade e os grandes volumes gerados.

A coleta de informações disponíveis a respeito do manejo de resíduos e das condições ambientais nestes estabelecimentos foi feita através da aplicação de questionários com os administradores de cada serviço de saúde. Os questionários foram elaborados com questões objetivas com base na legislação vigente a respeito do manejo dos Resíduos de Serviços de Saúde (RSS): RDC CONAMA 358/2005 e RDC ANVISA 304/2004, NR-32 do Ministério do Trabalho e Emprego.

A organização dos dados coletados foi feita em planilha do Excel onde se realizou a tabulação das respostas dos questionários, permitindo sua fundamentação teórica, interpretações e sínteses. Os dados coletados nesta fase foram analisados em outros capítulos que compõe a dissertação resultante deste estudo. Entretanto, os problemas, questionamentos e sugestões identificados no diagnóstico preliminar evidenciaram a necessidade de intervenção no campo da educação ambiental em saúde através da pesquisa-ação. 


\section{$3^{\text {a }}$ Fase - Campo de Observação, Amostragem e Representatividade Qualitativa}

Esta fase caracterizou-se por delimitar e caracterizar o campo de estudo. $\mathrm{O}$ Município de Mossoró está situado na mesorregião Oeste do estado do Rio Grande do Norte, com área de $2.110 \mathrm{~km}^{2}$ e população 226.975 habitantes. De acordo com o relatório da Pesquisa Nacional de Saneamento Básico- PNSB/2008 o município possui 178 unidades de saúde (hospitais, clínicas, consultórios odontológicos e atendimentos ambulatoriais, unidades básicas de saúde, etc.), e 961 leitos distribuídos entre as esferas públicas e privada e em diversas especialidades (IBGE, 2008).

Para a concretização da metodologia proposta considerou-se ser operacionalmente inviável o desenvolvimento das atividades em todos os estabelecimentos de saúde da cidade. Assim, optou-se pela amostragem intencional dos estabelecimentos de saúde, de representatividade qualitativa e quantitativa, cujo critério foi à inserção destes em algum nível de complexidade do SUS (Atenção Básica, Média e Alta complexidade) havendo a necessidade de recortes quanto ao número de estabelecimentos onde seriam realizadas as atividades educativas. Assim, para a realização das atividades educativas foram selecionados três estabelecimentos públicos de saúde em diferentes níveis de complexidade: uma unidade básica de saúde, um hospital para doenças infecto-contagiosas, um hospital para urgências e emergências.

\section{$4^{\mathrm{a}}$ Fase - Estratégia e Plano de Ação - Descrição das Atividades}

Após a identificação das necessidades nos estabelecimentos de saúde foram propostas ações educativas, tanto pela pesquisadora como pelos gestores e trabalhadores consolidando uma relação dialógica na construção de saberes entre a pesquisadora e os sujeitos da pesquisa. As ações foram organizadas de acordo com a adesão às propostas educativas pelos administradores e trabalhadores a fim de realizar intervenções no campo da educação em saúde ambiental nestes serviços.

As ações educativas foram realizadas através de parcerias com diferentes setores destes estabelecimentos, como: Núcleo de Saúde do Trabalhador, Comissão de Controle de Infecção Hospitalar - CCIH, Núcleo de Vigilância Epidemiológica Hospitalar NVEH, Comissão Interna de Prevenção de Acidentes - CIPA, Coordenação de Enfermagem, Setor de Higienização e Limpeza, Administração Hospitalar e funcionários de um modo geral. O processo de abordagem da temática ambiental com estes profissionais foi feito de acordo com as características de cada serviço abordando 
aspectos relacionados às questões estruturais, as atividades profissionais, os serviços oferecidos e os aspectos legais e normativos envolvidos.

As diferentes atividades educativas em saúde ambiental nestes serviços foram ministradas com auxílio de apostilas, retro-projetor, projetor de multimídia, folders e cartazes para divulgação e cartilha educativa. Ao final de cada atividade vivenciada, os questionamentos e observações mais freqüentes abordados pelos participantes, foram anotados em "caderno de campo", para posterior análise. Lavoe, Marquis \& Laurin (1996) consideram este "instrumento necessário na consolidação dos dados recolhidos durante todo o processo de pesquisa, de forma a objetivar o vivido e o compreendido".

Os sujeitos da pesquisa foram os profissionais de saúde efetivos e terceirizados vinculados ao quadro de servidores destes serviços. As atividades de educação ambiental em saúde desenvolvidas durante a pesquisa transcorreram a partir do mês de março até o mês de outubro de 2007, totalizando quinze atividades educativas em saúde ambiental: manejo de resíduos, controle de vetores, efluentes líquidos e gasosos e normas de biossegurança.

As atividades distribuíram-se da seguinte forma: Semana de saúde (01), cursos sobre RSS (03), mesa redonda: risco no manuseio de RSS (01), participação na I Semana Interna de Prevenção de Acidentes do Trabalho - SIPAT do hospital de urgências (01), reuniões rápidas nos setores clínicos com os funcionários da enfermagem (04), reuniões com funcionários da higienização (05). São descritas a seguir as atividades desenvolvidas de acordo com a ordem cronológica de acontecimento das mesmas.

\section{- I Semana de Saúde do Hospital público referência em urgências e emergências}

A organização da Semana de Saúde do Hospital Regional Tarcísio Maia (HRTM) surgiu a partir do diagnóstico de pesquisa e da necessidade de incrementar o processo de educação continuada nesta instituição. O evento teve duração de cinco dias consecutivos do mês de março de 2007. A comissão organizadora teve a seguinte composição: A pesquisadora (bióloga), uma enfermeira da Comissão de Controle de Infecção Hospitalar, uma enfermeira do núcleo de vigilância epidemiológica hospitalar, o administrador do hospital e três técnicos administrativos. O local foi o auditório da faculdade de medicina da Universidade do Estado do Rio Grande do Norte - UERN cuja edificação é extensiva ao hospital facilitando a participação dos funcionários.

$\mathrm{Na}$ programação foram abordadas temáticas correspondentes aos principais problemas identificados na fase de diagnóstico dos estabelecimentos referentes às 
condições do ambiente de trabalho desses profissionais. Como se tratava de um evento diferenciado no setor saúde no município de Mossoró-RN os temas abordados durante o evento contemplaram diferentes áreas de interesse dos profissionais da atenção básica, média e alta complexidade e dos gestores. Neste contexto, foi importante a participação de outros profissionais de saúde de diferentes serviços de saúde da cidade, como: unidades básicas de saúde, secretarias municipal e estadual de saúde, hospitais, laboratórios e clínicas do município.

As palestras foram distribuídas pelos cinco dias abordando os seguintes temas: educação ambiental em saúde, resíduos de serviços de saúde, acidentes ocupacionais com perfurocortantes, recomendações em caso de exposição ao material biológico, doenças ocupacionais, biossegurança, dentre outros. A divulgação da semana foi feita através de folders, camisetas, cartazes, faixas, mídia, etc. Aos participantes inscritos foram distribuídos cartilhas educativas, certificados, crachás, bolsas e premiações (doadas pelo comércio local). O público presente durante todo o evento foi em torno de 1.300 pessoas.

\section{- Curso básico sobre resíduos de serviços de saúde}

O curso sobre resíduos de serviços de saúde foi elaborado pela pesquisadora para profissionais que atuam nos estabelecimentos de saúde de alta complexidade. A proposta para a realização do curso foi feita aos departamentos de Saúde do Trabalhador e de Recursos Humanos do Hospital público referência em urgência e emergência. Foram oferecidas três turmas para 40 participantes distribuídas assim: $1^{\mathrm{a}}$ turma em abril, $2^{\mathrm{a}}$ em julho e $3^{\mathrm{a}}$ em outubro de 2007.

A carga horária foi de $20 \mathrm{~h} /$ aula com direito a certificado e o curso foi ministrado pela bióloga/pesquisadora. Cada curso foi realizado no período de dois dias nas instalações do próprio estabelecimento iniciando às $13 \mathrm{~h}$ e encerrando às $17 \mathrm{~h}$. Para facilitar o acompanhamento do tema abordado pelos participantes foi confeccionada uma apostila abordando a temática ambiental em saúde distribuído em cinco eixos principais:

Meio ambiente: conceitos, educação ambiental, poluição ambiental e sustentabilidade.

Controle de vetores: pragas urbanas, fatores que contribuem para o aumento dos vetores, controle, medidas preventivas.

Qualidade da água para abastecimento humano: doenças relacionadas à transmissão hídrica, armazenamento, qualidade e controle da água.

Efluentes líquidos e gasosos: públicos, domésticos e especiais. 


\section{Manejo de RSS: Discutindo a NR-32/2005 e as RDC: 358/2005 CONAMA e} 306/2004 ANVISA. Resíduos sólidos, controle de riscos (físicos, químicos e biológicos), biossegurança, classe de riscos, medidas preventivas para acidentes com perfurocortantes.

- Palestra: riscos no manejo de resíduos infectantes

As palestras foram organizadas para os diferentes estabelecimentos de saúde abordando questões referentes ao manejo interno dos RSS, meio ambiente e educação ambiental. Foi realizada uma palestra em cada estabelecimento o público participante ficou em torno de 30 pessoas por palestra;

- Reuniões nas enfermarias com pacientes, acompanhantes e funcionários.

Essas atividades não foram planejadas, mas o desdobramento das outras atividades desenvolvidas no mesmo período. O público presente oscilava entre quatro a dez pessoas por reunião com duração média de quinze minutos. Houve interesse por parte dos pacientes e acompanhantes em participar das conversas que recebeu respaldo dos profissionais e gestores dos estabelecimentos diante da importância do tema para a melhoria das condições do ambiente dentro das enfermarias mediante acordo entre estes, os funcionários e a pesquisadora. Assim, várias palestras foram realizadas nos diferentes setores, conforme solicitação ou necessidade, em dias e equipes diferenciados, por um período aproximado de três meses. As temáticas eram referentes ao controle de pragas, descarte de resíduos, armazenamento de alimentos, etc.

\section{- Palestras exclusivas para funcionários da higienização e limpeza}

As palestras foram direcionadas aos profissionais da higienização e limpeza destes três estabelecimentos durante o turno de trabalho. Foi feita uma abordagem voltada para o correto manejo de resíduos produzidos em suas diferentes etapas: descarte, armazenamento interno, transporte e destino final dos RSS. Foram feitas orientações sobre as normas de biossegurança e informações sobre as resoluções ANVISA e CONAMA que regulamentam o gerenciamento e destino final dos resíduos de serviços de saúde diante da necessidade de conhecer e cumprir estas normas. As orientações foram feitas no horário de intervalo de trabalho (lanche) para o conjunto de profissionais escalados naquele dia com duração em torno de meia hora

\section{- I Semana Interna de Prevenção de Acidentes de Trabalho do HRTM}

Participação em "mesa redonda" sobre riscos no ambiente hospitalar, com público de 40 profissionais do hospital referência em urgências e emergências, 
abordando os diferentes riscos no ambiente hospitalar: Riscos físicos (Técnico/SENAI), riscos químicos (Bioquímica), riscos biológicos (Bióloga/Pesquisadora).

\section{$5^{\text {a }}$ Fase - Aprendizagem: Troca Mútua de Informações}

Durante a realização das atividades educativas, foram apresentados vários questionamentos pelos participantes a respeito dos problemas ambientais destes estabelecimentos. A principal estratégia didática utilizada durante as atividades educativas foi à exposição dialogada. Mas, utilizou-se outros recursos didáticos como apostila, cartazes, multimídia, dentre outros. Utilizou-se lousa branca e folha de papel madeira para fazer anotações dos pontos mais destacados pelo grupo, para chamar atenção dos participantes sobre suas abordagens e de sua contribuição na busca coletiva da solução dos problemas em seu ambiente de trabalho. As dúvidas e questionamentos apresentados foram registrados em "caderno de campo" para posterior análise qualitativa pela pesquisadora. De acordo com Franco (2005), no processo de coleta de dados, registrá-los coletivamente, discuti-los e contextualizá-los, já se está caminhando para a construção dos saberes e para seu compartilhamento.

\section{$6^{\text {a }}$ Fase - Avaliação}

A maior parte das atividades educativas se desenvolveu nas instalações dos próprios estabelecimentos de saúde (lócus da pesquisa) a fim de permitir a participação e a troca de informações entre os funcionários. De acordo com Grittem et al (2008), a pesquisa-ação possibilita a utilização do conhecimento dos participantes e dos sujeitos envolvidos na pesquisa transformando-os em agentes colaboradores e capazes de propor e implementar mudanças nas suas atividades práticas.

Dificuldades estiveram presentes durante todo o processo de pesquisa. Problemas de ordem estrutural como: cadeiras insuficientes, ausência de local adequado para as reuniões, inexistência de instrumentos pedagógicos, dentre outros fatores necessários ao incremento das atividades educativas. Contudo, reconhecemos a relevância dessas atividades educativas com a temática da saúde ambiental nos serviços de saúde, principalmente, quando se considera o tempo dispensado por esses profissionais para discutirem a temática ambiental em seus horários de trabalho ou nos seus dias de descanso.

Quanto à participação e abordagem dos profissionais nas atividades considerouse satisfatória. Ainda que sem a participação da maioria dos funcionários, sobretudo, 
nos hospitais onde a demanda por atendimentos a pacientes é proporcionalmente maior, em que se limitou a participação de uma parcela destes profissionais por setor naqueles horários. Entretanto, não se pode deixar de mencionar o desinteresse e a crítica de alguns profissionais em relação às atividades desenvolvidas abordando a temática ambiental sobre o argumento de necessitarem de assuntos mais específicos relacionados com a assistência ao paciente. Durante o período das atividades não foi proposto aos participantes nenhum tipo de avaliação escrita. No entanto, houve espaço para o debate, durante e após cada momento, para que os participantes pudessem opinar a respeito de suas impressões sobre as atividades que participaram.

Em contrapartida, constatou-se a presença significativa dos profissionais que formam os quadros da enfermagem e da higienização. Fato considerado relevante uma vez que estes profissionais vivenciam continuamente o ambiente e a rotina dos serviços de saúde e por se tratar de uma categoria que efetua o descarte de resíduos e de outra que operacionaliza o seu manejo nas demais etapas do gerenciamento de RSS. Mas, a maioria destes profissionais expressa indiferença quanto aos procedimentos técnicos necessários ao manejo dos resíduos, independentemente da demanda de atividades que desempenham no dia-a-dia (ALVES, 2008).

A proposição discutida neste artigo significou o início de um processo educativo em saúde ambiental nos serviços de saúde que necessita ser incorporado pelos gestores e profissionais de saúde. Deverá ser um artifício essencial dentro da política estratégica de educação permanente do SUS que visa diminuir os riscos e acidentes ocupacionais dentro dos serviços de saúde. Sobretudo, nesse momento em que se necessita e se exige mudanças de mentalidade e de postura da sociedade, dos gestores públicos e profissionais dos diferentes setores frente aos problemas ambientais cujos efeitos maléficos recaem sobre a coletividade, causando danos a saúde humana e ao meio ambiente. Levando-nos a reflexão sobre a necessidade de mudanças que contribuam e promovam a saúde dos indivíduos e de ambientes saudáveis. Inclusive, os aspectos fundamentais e particulares, não só das questões ambientais do setor saúde, mas, sobretudo do reconhecimento individual e coletivo das responsabilidades sobre as condições do ambiente de trabalho em saúde percebidas de uma forma mais abrangente.

Não foi objetivo traçado para essas atividades a tentativa de mudanças da situação ambiental desfavorável diagnosticada nestes serviços. Mas, a tentativa de contribuir para que o conjunto dos profissionais de saúde incorporasse o saber ambiental as suas atividades profissionais cuja, compreensão se faz necessária no processo saúde- 
doença. Sobretudo, a reflexão sobre a necessidade de mudanças de atitudes que contribuam e promovam a saúde dos indivíduos e do meio ambiente dentro e fora dos estabelecimentos de saúde. E a percepção de que esta realidade não está desvinculada da problemática ambiental que vivenciamos hoje no mundo. Não obstante, mostraram-se dispostos a colaborar com a melhoria da qualidade ambiental de seus ambientes de trabalho mediante a adoção de medidas e atitudes preventivas contribuindo, principalmente para a diminuição dos acidentes ocupacionais no âmbito hospitalar.

\section{CONSIDERAÇÕES FINAIS}

A oportunidade de conhecer, discutir e propor ações educativas que promovam a atenuação dos problemas ambientais nos serviços de saúde foi uma experiência singular. Ao passo que proporcionou a construção do conhecimento no cotidiano do campo de pesquisa em sua dimensão prática. A flexibilidade metodológica da pesquisa-ação permitiu o planejamento e a realização de atividades educativas no decorrer da pesquisa proporcionando resultados satisfatórios para os sujeitos e as instituições envolvidas.

Durante o processo de pesquisa foram coletados dados, informações e depoimentos que não necessitaram ser analisados em sua totalidade. Entretanto, configuram-se como um rico conteúdo que auxiliaram a análise dos resultados da pesquisa podendo ser apreciados em discussões posteriores. Como afirma Thiollent (2009), "uma pesquisa é sempre mais rica do que aquilo que se pode narrar, pois os sujeitos da pesquisa fornecem informações que não estavam previstas, aumentando a riqueza das descrições".

Finalmente, a análise assinala a necessidade de investimentos estruturais e educacionais nestes serviços bem como em pesquisas que contribuam para a compreensão dessa problemática no contexto da sociedade moderna apontando caminhos e soluções eficazes dentro de uma perspectiva ética em que a qualidade de vida dos cidadãos possa se consolidar como um princípio fundamental na construção de uma sociedade democrática e sustentável.

\section{BIBLIOGRAFIA}

ALVES, M. L. (2008). A saúde ambiental e os resíduos de serviços de saúde nos três níveis de complexidade do Sistema Único de Saúde - SUS. [Dissertação de Mestrado]. Natal: Programa Regional de Pós-Graduação em Desenvolvimento e Meio Ambiente/PRODEMA. Universidade Federal do Rio Grande do Norte-UFRN. 
AUGUSTO, L.G.S. (2002). A construção de indicadores em saúde ambiental: desafios conceituais. In: MINAYO, M.C.C., MIRANDA, A.C; (org.). Saúde e ambiente sustentável: estreitando nós. Rio de Janeiro: FIOCRUZ; p. 291-312.

AUGUSTO, L.G.S.; FLORÊNCIO, L.; CARNEIRO, R. M. (2001). Pesquisa (ação) em Saúde Ambiental: contexto, complexidade, compromisso social. Recife: Ed. Universitária da UFPE.

BENEVIDES, R. \& PASSOS, E. (2005). Humanização na saúde: um novo modismo? Revista Interface, Comunic., Saúde e Educ. 9(17): 389-406.

BRASIL. (2004).Agência Nacional de Vigilância Sanitária. Resolução no 306 de 07 de dezembro de 2004. Dispõe sobre o regulamento Técnico para o gerenciamento de resíduos dos serviços de saúde. Diário Oficial da União 2004; 10 dez.

BRASIL. (2005). Conselho Nacional de Meio Ambiente. Resolução no 358 de 29 de abril de 2005. Dispõe sobre o tratamento e Disposição final dos resíduos dos serviços de saúde e dá outras providências. Diário Oficial da União 2005; 4 mai.

BRASIL. (2006). Ministério da Saúde. Pactos pela vida, em defesa do SUS e de Gestão - diretrizes operacionais. Série Pactos pala saúde 2006. Vol. 1. Departamento de Apoio a Descentralização/Secretaria Executiva, Brasília.

BRASIL. Ministério do Trabalho e Emprego. Portaria $n^{\circ} 485$, de 11 de Novembro de 2005. NR 32 - Segurança e Saúde no Trabalho em Serviços de Saúde. Diário Oficial [da] República Federativa do Brasil, Brasília, DF, 16 nov. 2005. Disponível em: http://portal.mte.gov.br. Acesso em: 20 fev. 2013.

ENGEL, G.I. (2000). Pesquisa-ação. Educar, Curitiba, n. 16, p. 181-191. Editora da UFPR.

FRANCO, M.A.S. (2005). Pedagogia da pesquisa-ação. Educação e Pesquisa. São Paulo, v.31, n.3, p. 483-502, set/dez.

FREIRE, P. (1993). Pedagogia do Oprimido. São Paulo: Paz e Terra.

FUNASA. (2000). Fundação Nacional de Saúde. Curso básico de vigilância ambiental. Módulo I. Brasília: Funasa.

GARCÍA, R. (1999). Interdisciplinaridad y sistemas complejos. In: Confederación de Trabajadores de la Educación de La Republica Argentina. Educación en Ambiente para El Desarrollo Sostenible. Buenos Aires. p. 39-66.

GATTI, B. (2002). A construção da pesquisa em educação no Brasil. Brasília: 2002, Plano. (Série Pesquisa em educação, v.1).

GRITTEM, L.; MÉIER, M. J.; ZAGONEL, I.P.S. (2008). Pesquisa-ação: uma alternativa metodológica para pesquisa em enfermagem. Texto \& Contexto Enfermagem, Florianópolis, Out-Dez; 17(4): 765-70. 
IBGE - INSTITUTO BRASILEIRO DE GEOGRAFIA E ESTATÍSTICA. Disponível em: http://www.ibge.gov.br/home/estatistica/populacao/condicaodevida/pnsb2008 . Acesso em: 18 ago. 2012.

KETELE, J.; ROEGIERS, X. (1993). Méthodologie du recueil d'informations: fondements de méthodes d'observations de questionaires, d'interviews et d'étude de documents. 2. ed. Bruxelles: De Boeck Université. p. 99.

LAVOE, L. MARQUIS, D. LAURIN, P. (1996). La recherché-action: théorie et pratique. (Manuel d'autoformation). Canadá: Presses de l'Université du Québec.

LIEBER, R. R. (1998) Teoria e metateoria na investigação da causalidade: o caso do acidente de trabalho. São Paulo (SP): USP.

MOLINA, R. (2007). A pesquisa-ação/investigação-ação no Brasil: mapeamento da produção (1966-2002) e os indicadores internos da pesquisa-ação colaborativa. (Tese) Faculdade de Educação, Universidade de São Paulo, São Paulo. 2007.

MOREIRA, A.F. (2007). Ambientes de Aprendizagem no Ensino de Ciência e Tecnologia. Belo Horizonte: CEFET-MG. Notas de aula.

NUNAN, D. (1993). Action research in language education. In: EDGE, J.; RICHARDS, K. (Ed.). Teachers develop teachers research. Papers on classroom research and teacher development. Oxford: Heinemann, p. 41.

SAMAJA, J. (2000). A reprodução social e a saúde: elementos metodológicos sobre a questão das relações entre saúde e condições de vida. Salvador, Ed. ISC-UFBA /Casa da saúde.

SCHALL, V.T. \& STUCHINER, M. (1999). Editorial: Educação em saúde: novas perspectivas. Cad. Saúde Pública; 15(2): 4-5.

THIOLLENTE, M. (2009). Metodologia da pesquisa-ação. 17. ed. São Paulo: Cortez, $112 p$.

TRIPP, D. (2005). Pesquisa-ação: uma introdução metodológica. Educação e Pesquisa, São Paulo, v. 31, n. 3, p. 443-466, set./dez.

UNESCO. Década da Educação das Nações Unidas para um desenvolvimento Sustentável, 2005-2014: documento final do esquema internacional de implementação. Brasília: UNESCO, 2005. 120p. 